\title{
DNA Binding Mode of the Isoquinoline Alkaloid Berberine with the Deoxyoligonucleotide d(GCCGTCGTTTTACA) 2
}

\author{
Hye-seo Park, ${ }^{+\$}$ Eun Hee Kim,, Yoon-Hui Sung, ${ }^{\dagger}$ Mi Ran Kang, ${ }^{+\$}$ In Kwon Chung, \\ Chaejoon Cheong," and Weontae Lee ${ }^{\dagger+s^{\circ}}$ \\ ${ }^{\dagger}$ Department of Biochemistry, $=$ Department of Biologv, \\ SProtein Network Research Center, Yonsei Chiversitv, Seoul 120-749, Korea \\ "Magnetic Resonance Team, Korea Basic Science Institute. 52 Eoun-dong. Yusung-gu, Daejeon 305-333, Korea \\ Received March 3, 2004
}

\begin{abstract}
The ability of protoberberine alkaloids. berberine and berbernbine, to act as topoisomerase II poisons is linked to the anti-cancer activity. Minor alterations in stnicture have a significant effect on their relative activity: Berberine. which has methoxy group at the 19-position, is significantly less potent than berbernbine. Several observations support non-specific binding to HPIt by the berberine: (i) nonspecific upfield changes in ${ }^{~} \mathrm{H}$ chemical shift for protons of the berberine: (ii) the broadening of imino protons of HPI4 upon binding of the berberine: (iii) very small increases in duplex melting temperature in the presence of the berberine. Our results reveal that substitution of a hydroxyl group to a methoxy group on the 19-position, thereby converting the berberrubine to the berberine is associated with a non-specific DNA binding affinity and a reduced topoisomerase II poisoning. The presence of a bulky 19-methoxy substituent decreases intercalating properties of berberine and makes it inactive as topoisomerase II poison.
\end{abstract}

Key Words : Berberine, Topoisomerase II poison, DNA binding. NMR

\section{Introduction}

All eukaryotic cells contain two major classes of topoisomerases. Members of these classes are referred to as type I or type II topoisomerases and can be distinguished on the basis of their physical and mechanistic properties. ${ }^{1-4}$ Type II topoisomerase interconvert topological forms of DNA by making transient double-stranded breaks in the backbone of the genetic material. With the discovery that these enzymes were cellular targets for a number of clinically important antineoplastic agents, ${ }^{5-8}$ the scope of interest in topoisomerases rapidly expanded to include both the pharmacologist and the oncologist. Rather than blocking the critical physiological functions of this enzyme, the topoisomerase IItargeted drugs poison the essential type II enzyme by increasing the steady-state concentration of their covalent DNA cleavage complexes. ${ }^{9-12}$ Consequently. these drugs convert type II topoisomerase into potent toxins that generate high numbers of double-stranded breaks in the genomes of treated cells.

The protoberberine alkaloids, such as berberine (Fig. l(a)). are among the most widely distributed alkaloids of the isoquinoline series and are a new class of organic cations that exhibit topoisomerase poison activity. ${ }^{13-15}$ Berberrubine (Fig. I(b)) was shown to be inducers of topoisomerase IIDNA cleavable complexes. whereas the structurally similar berberine showed no poison activity for topoisomerases II. ${ }^{16}$ Furthermore. it has been shown that berberrubine and its derivatives exhibit antitumor activity in mouse models. and a

\footnotetext{
"To whom correspondence should be addressed: Fax: +82-2-3632706: Tel: +82-2-2123-2706; e-mail: wlee aspin.yonsei.ac.kr
}

hydroxyl group at the 19-position of berberrubine is essential for the manifestation of antitumor activity. ${ }^{17}$

However. the mechanism of action of these drugs that target topoisomerase II is much less clear. Their reported experimental result and suggested mechanism (an intercalation or a groove binding) is still controversial. ${ }^{18-22}$ To better understand the mechanisms, we characterize the DNA (HPl4; Fig. l(c)) binding properties of berberine in this work. which differ in the chemical structures of the 19position from berberrubine by UV and NMR spectrometry.

\section{Experimental Section}

Materials \& Methods. Berberine was obtained from Sigma and kept as a 10 or $40 \mathrm{mM}$ stock solution in $\mathrm{D}_{2} \mathrm{O}$ or $90 \% \mathrm{H}_{2} \mathrm{O} / 10 \% \mathrm{D}_{2} \mathrm{O}$. The deoxyoligonucleotide $\mathrm{d}$ (GCCGTCGTTTTACA) ( $\mathrm{HPl}$ ) which contains cleavage sites of topoisomerase II was obtained from J. L. Science (Taejon, Korea). The lyophilized HPl4 (Fig. I(c)) sample was dissolved in $0.45 \mathrm{~mL}$ of the degassed $\mathrm{H}_{2} \mathrm{O}$ buffer $(50 \mathrm{mM}$ potassium phosphate. $100 \mathrm{mM} \mathrm{NaCl}$. $0.01 \mathrm{mM}$ EDTA, pH 7.0). Then $0.05 \mathrm{~mL}$ of $99.96 \% \mathrm{D}_{2} \mathrm{O}$ was added to the sample. For the experiments on the non-exchangeable protons. the mixture was lyophilized 2 times from $\mathrm{D}_{2} \mathrm{O}$ and resuspended in $0.5 \mathrm{~mL}$ of $100 \% \mathrm{D}_{2} \mathrm{O}$.

NMR spectroscopy. All NMR spectra were acquired on a Bruker DRX-600 and DRX-500 spectrometer in quadrature detection mode. equipped with a triple-resonance probe with an actively shielded pulsed field gradient (PFG) coil. Chemical shifts for ${ }^{l} \mathrm{H}$ are reported relative to tetramethylsilane (TMS) at $0.00 \mathrm{ppm}$. All two-dimensional experiments were performed at $298 \mathrm{~K}$. Pulsed-field gradient tecluniques 
(a)

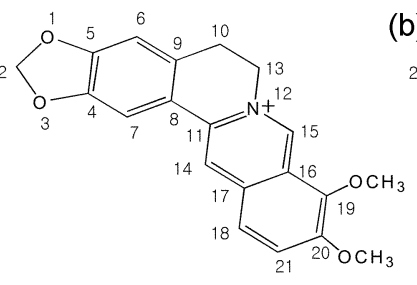

Berberine (1) (b)

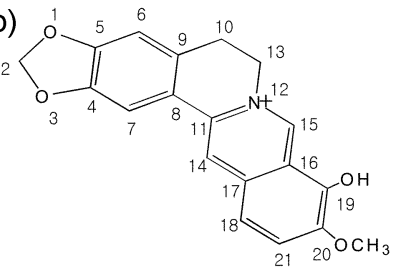

Berberrubine (2) (c)

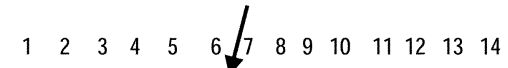

$$
\begin{aligned}
& \text { 5'-GCCG TCGTTT TACA-3' } \\
& \text { 3'-CGGCAGCAAAAATG T-5' } \\
& \begin{array}{l}
\text { Topoisomerase II cleavage site of } \\
\text { berberrubine }
\end{array}
\end{aligned}
$$

Figure 1. Chemical structures of berberine (a) and herberrubirle (b) The alomic numbering and ring lettering are indicated in their structure. Berberine has two methoxy groups at positions 19 and 20. whereas berberrubine has hydroxyl group at position 19. (c) A consensus ID.VA 14-mer $\mathrm{HP}^{3} 4$ containing a pulative topoisomerase II medialed cleavage sile.

were used for all $\mathrm{H}_{2} \mathrm{O}$ experiments, resulting in good suppression of the solvent signal. Solvent suppression was achieved by utilizing pulsed-field gradient technicpues for all $\mathrm{H}_{2} \mathrm{O}$ experiments. Fxchangeable proton spectra were obtained using the 1-1 (jump-return) method. The 2D spectra were acquired with 400 or 512 FIDs of 2048 complex data points, $6000 \mathrm{~Hz}$. for spectra acquired in $\mathrm{D}_{2} \mathrm{O}$ and $12000 \mathrm{~Hz}$. for spectrat acquired in $\mathrm{H}_{2} \mathrm{O}$. The repetition delays were set to 2 sec, and 40-64 scans were averaged for each FID. All NMR data were processed using XWIN-NMR (Bruker). Twodimensional nuclear Overhauser effect spectroscopy (NOFSY) spectra ${ }^{2.3}$ of free DNA and drugs, berberrubine and berberine bound DNA were recorded with mixing times of $150 \mathrm{~ms}$ and $400 \mathrm{~ms}$. Total correlation spectroscopy (lOCSY) spectra ${ }^{24}$ was acquired in $\mathrm{H}_{2} \mathrm{O}$ solution with a mixing time of $60 \mathrm{~ms}$ using MLEVI7 spin lock pulses, and double quantumfiltered (DQF) COSY spectra ${ }^{25}$ were collected in both $\mathrm{H}_{2} \mathrm{O}$ solutions to get vicinal coupling constants for both free and DNA-drug complex samples. All experiments were performed in the phase sensitive mode using the time proportional phase incrementation ( [ P JPI) method. The NMR data were processed using the nmrlipe/NMRDraw software packages (Biosym/Molecular Simulations, Inc.) and XWINNMR (Bruker Instruments) software. The NMR spectra were analyzed using the Sparky 3.60 software.

UV spectroscopy. Absorbance versus temperature profiles were measured at $260 \mathrm{~nm}$ on a Varian Cary 400 (Sidney, Australia) spectrophotometer equipped with water circulated cellblock. Melting transitions were monitored with the cellblock temperature and measured at $260 \mathrm{~nm}$ with a $1.5 \mathrm{sec}$ averaging time. The temperature was raised in $1{ }^{~} \mathrm{C} / \mathrm{min}$ increments, and samples were allowed to equilibrate for 30 sec at each temperature setting. For each optically detected

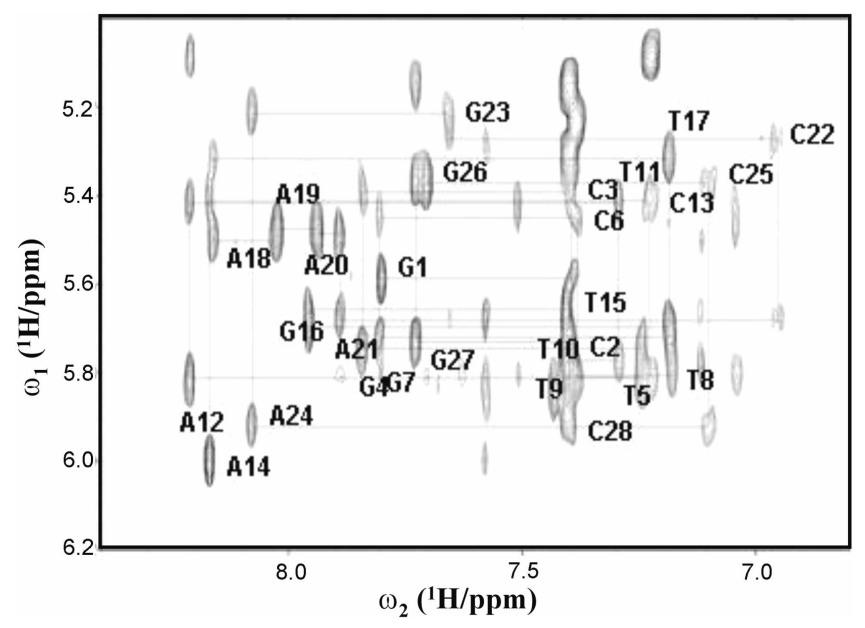

Figure 2. The NOESY spectrum of HPI4 + berherine $(1: 1)$ in 100 $\mathrm{m.M}$ KC. $.50 \mathrm{mM}$ phosphate buller. and $\mathrm{pH} 7.0$ in $\left[\mathrm{D}_{2} \mathrm{O}\right.$ at 5 " $\mathrm{C}$. (mixing lime $300 \mathrm{msec}$ ) (Intraresidue and Secluential connectivilies between $\mathrm{III}$ and $6[$ or $81 \mathrm{I}$ ).

transition, the melting temperature $\left(T_{\mathrm{m}}\right)$ was determined as previously described by hyperchromicity method. ${ }^{26}$ For calculating of $\mathrm{T}_{m}$, a linear least squares line is calculated and extrapolated to both ends of the melting curve.

\section{Results}

Resonance Assignments. DNA duplex assignments were based on the presence of distinct base proton $(\mathrm{H} 8, \mathrm{H} 6, \mathrm{H} 5$, and $\mathrm{TMe}$ ) to sugar proton secuential NOF connectivities. ${ }^{27}$ Spectra of the free duplex were unambiguous; ${ }^{28}$ assignments for bound duplex rely on observable sequential connectivities, similarities to patterns observed for free duplex. and exchange peaks observed in NOFSY experiments between perturbed and unperturbed resonances (Fig. 2 and Table 1). In both cases, the NOF connectivities were consistent with a B conformation throughout the length of the HP14 duplex.

The proton resonances of free berberine in $\mathrm{D}_{2} \mathrm{O}$ were assigned according to the previously reported method by ${ }^{1:} \mathrm{C}$ HSQC and HMBC NMR spectra in our group (Table 2). ${ }^{29}$ Due to overlap on the water resonance, it was not possible to locate bound $\mathrm{H} 13$ protons of the berberine directly.

Chemical Shift Variation $\left(\Delta \delta_{\text {vourd }}-\delta_{\text {iree }}\right)$ and Temperature Dependence of ' $H$ NMR Resonances. The addition of the berberine to a solution of the double helix fragment $\mathrm{HPl} 4$ induces broad proton resonances of imino proton region of $\mathrm{HP}^{\mathrm{l}} 4$ even at low drug/DNA ratio (rig. 3). The resonances of the berberine move up-field with respect to the free drug. The binding process is intermediate rate with respect to the NMR time scale, as no separate signals of $\mathrm{HPl} / 4$ were observed for the free and the bound species, even at low temperature $\left(5{ }^{\circ} \mathrm{C}\right)$ ( $\left.\mathrm{rig} .4\right){ }^{28}$ The chemical shift values and the shift variation of the berberine protons. obtained by addition of the drug to HP14, are reported in lable 2 and tig. 5.

Differences in binding by these ligands are evident not only in resonance positions but also in exchange dynamics. 
Table 1. Proton NMR chemical shift assignments" of HPI 4 combined with Berberine in $90 \% \mathrm{H}_{2} \mathrm{O} / 10 \% \mathrm{D}_{2} \mathrm{O}$ solution

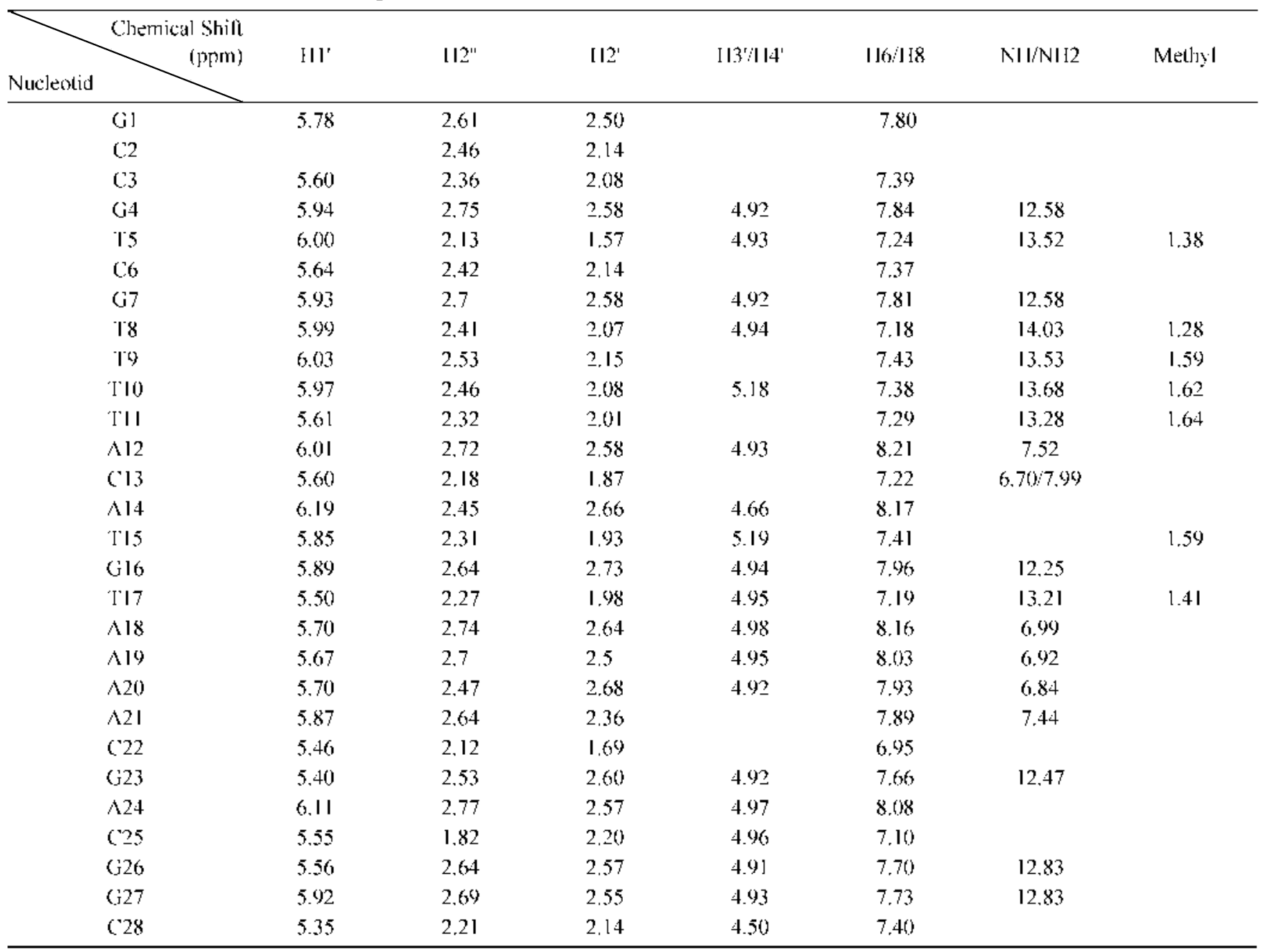

"Chemical shifis for ' $\mathrm{H}$ are reported relative 10 tetranethy Isilane (T'MS) at $0.00 \mathrm{ppm}$.

Table 2. 'If chemical shilt assignments for berberine in the presence of oligonucleotide $1 \mathrm{PI} / 4$ in $90 \% \mathrm{H}_{2} \mathrm{O} / 10 \% \mathrm{D}_{2} \mathrm{O}$ solution

\begin{tabular}{ccc}
\hline & \multicolumn{2}{c}{ Berberine (ppm) } \\
\cline { 2 - 3 } & liee & Complex \\
\hline HI0 & 3.13 & 3.09 \\
Methyl & 4.00 & 3.98 \\
HI3 & - & - \\
H2 & 6.00 & 5.98 \\
HI8 & 7.90 & 7.83 \\
H6 & 6.88 & 6.82 \\
H2I & 7.96 & 7.91 \\
H7 & 7.46 & 7.43 \\
HI4 & 8.47 & 8.36 \\
HI5 & 9.54 & 9.48 \\
\hline
\end{tabular}

In this NMR study of DNA binding by the berberine, we furthermore observe significantly broader lines compared to the bound berberrubine (Fig. 3). ${ }^{28}$ which are indicative of differences in exchange behavior between the two protoberberine analogs. Broader lines in spectra for the berberine may be attributed either to a reduced binding specificity and/

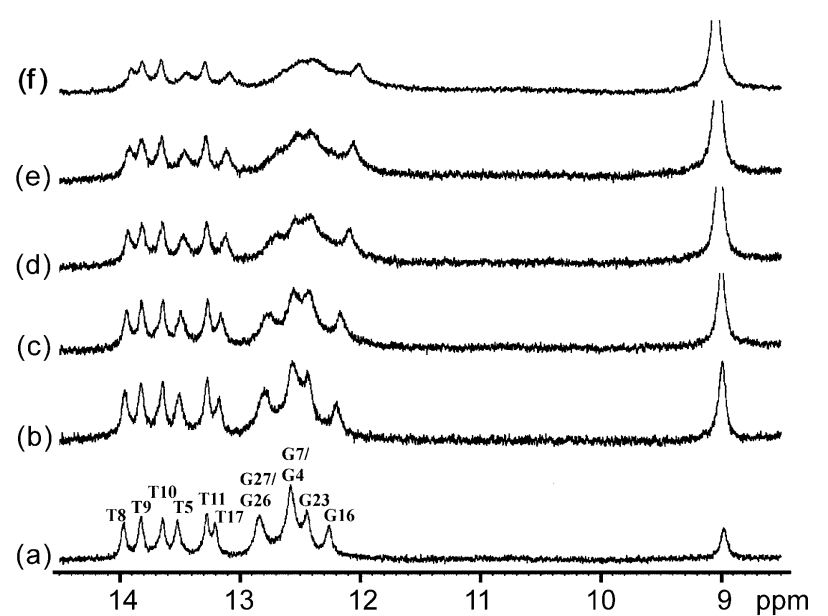

Figure 3. The imino proton region of $I D-{ }^{\prime} H$. VMR spectra of complex acquired at $5^{\circ} \mathrm{C}$ in $100 \mathrm{mM} \mathrm{KCI} 50 \mathrm{mM}$ phosphate bulfer and pld 7.0 in $90 \% \mathrm{H}_{2} \mathrm{O} / 10 \% \mathrm{D} \mathrm{I}_{2} \mathrm{O}$. The mole ralio belween IIPI4 and berberine is (a) $1: 0$ (b) $1: 1$ (c) $1: 2$ (d) $1: 3$ (c) $1: 4$ (f) $1: 5$

or to a somewhat faster exchange rate compared to the berberrubine. As also reported. ${ }^{30-3.3}$ we observe intermediate 


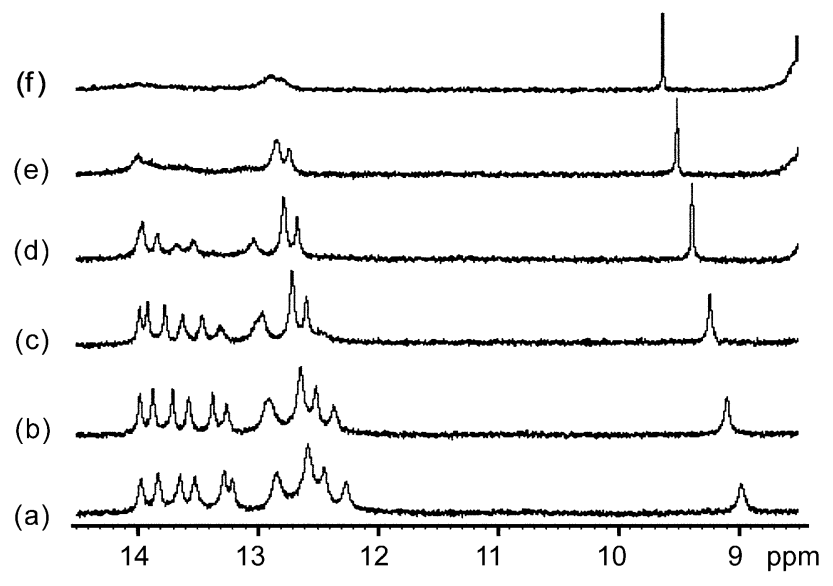

Figure 4. Variable-lemperalure 'H NMR spectra of $1: 1 \mathrm{HP} / 4+$ berberine in $100 \mathrm{mM} \mathrm{KCl.} 50 \mathrm{m.M}$ phosphate buller and pll 7.0 in $90 \% 1]_{2} \mathrm{O} / 10 \% \mathrm{D}_{2} \mathrm{O}$. Chemical shifts are reported relative to TSP $(0$ ppm) at (a) $5^{\circ \prime} \mathrm{C}$ (b) $15^{\circ} \mathrm{C}$ (c) $25^{\circ} \mathrm{C}$ (d) $35^{\circ} \mathrm{C}$ (c) $45^{\circ} \mathrm{C}$ (f) $55^{\circ} \mathrm{C}$

exchange on the NMR time scale near ambient temperature.

While $1 \mathrm{D}$ studies in $90 \% \mathrm{H}_{2} \mathrm{O} / 10 \% \mathrm{D}_{2} \mathrm{O}$ clearly demonstrated up-field shifts and broadening of imino protons upon binding of the berberine, line widths in the berberine-HPl4 system preclude high-resolution two-dimensional studies under $90 \% \mathrm{H}_{2} \mathrm{O} / 10 \% \mathrm{D}_{2} \mathrm{O}$ conditions.

Intermolecular NOEs. In contrast to results found for the berberrubine, few intermolecular NOCs between the oligonucleotide HPl4 and the berberine protons could be assigned in any portion of NOFSY spectra. It did not allow building a model of the complex. If the berberine ligands spend little time in any one location in space, then there is also little time for NOC buildup. The line widths in these spectra are likely responsible for this observation. NMR spectra of the berberine bound to HPI 4 feature broader lines and smaller signal-to-noise ratios than do spectra of the berberrubine bound to $\mathrm{HP14},^{28}$ This trend results from either a difference in exchange rate between the berberine and the berberrubine complexes and/or differences in specificity of binding. The consistently poorer resolution observed in DNA-bound spectra containing berberine is in itself a

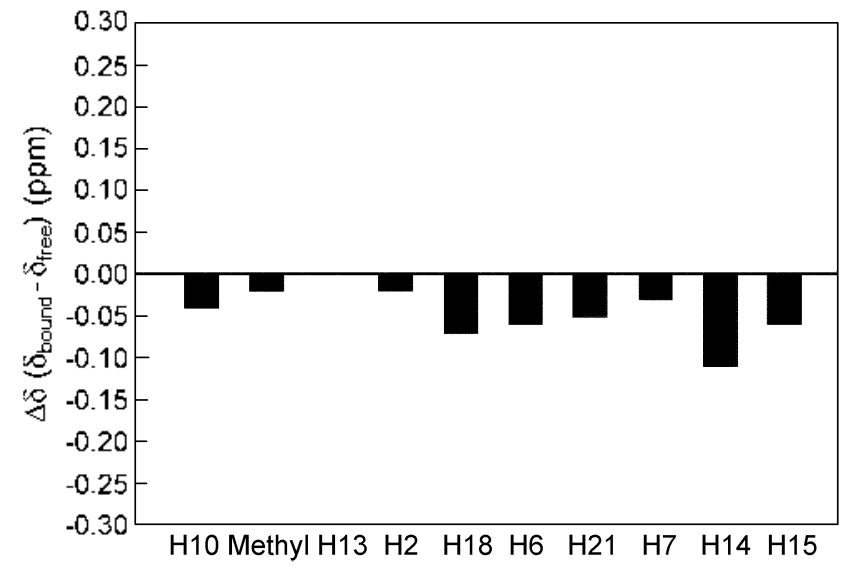

Figure 5. Plot of IIPI4-induced changes in 'II chemical shifts $(\Delta \delta$ $=\delta_{\text {bund }}-\delta_{\text {iree }}$ ) for protons of berberine. general indication of the poorer fit of the drug into the DNA double helix because of the steric hindrance caused by methoxy group on 19-position.

Duplex Melting Behavior. Thermodynamic stabilization of DNA duplexes is another binding property of potential biological significance. The values of the melting temperatures of the free and complexed oligonucleotides, as monitored by the change of the absorption maximum at 260 $\mathrm{nm}$, are reported in Table 3 . UV melting studies provided initial evidence that the berberine does not intercalate into $\mathrm{HP14}$. The melting temperature of the free HPl4 duplex is $63.0^{\circ} \mathrm{C}$. In the presence of the berberine, it increases to 63.7 ${ }^{\circ} \mathrm{C}$. In marked contrast to another intercalator, such as ethidium salt, ${ }^{31}$ the complex of the berberine with the HPl4 produces a virtually negligible gain in double helix stabilization. These small increases $\left(0.7-0.8^{\circ} \mathrm{C}\right)$ in melting temperature $\left(T_{11}\right)$ (Table 3 ) seen here in duplex DNA bound by the berberine further support non-intercalative binding of the berberine. The intercalation of small molecules into the double helix is known to increase the DNA melting temperature, ${ }^{35}$ at which the double helix denatures into single stranded DNA, owing to the increased stability of the helix in the presence of an intercalator.

\section{Discussion}

Despite much resemblance in chemical structure, berberrubine is a much more potent poison of topoisomerase II than berberine. As can be seen, ${ }^{\text {s-8 }}$ agents targeted to topoisomerase II are derived from a number of structurally diverse drug classes. One of the few properties shared by all drugs is the ability to bind to DNA. What can we therefore discern regarding differences for DNA binding mode between berberine and berberrubine? We have undertaken a multifaceted NMR study that probes the structural details of the interactions between the berberine and oligonucleotide HP14. Our interest is in placing the extensive biological data for this DNA binder in some structural context. Here, information is available directly from $1 D^{1} \mathrm{H}$ and $2 \mathrm{D}$ NOESY spectra of the berberine in the presence of $\mathrm{HP} 14$.

Chemical Shift Perturbations often accompany the binding of two biomolecules due to changes in the chemical environments of the atoms in the interface. Consequently, one goal of chemical shift analysis is to identify, in the absence of detailed structural information, the sites of local interactions between the two molecules. If the resonances

Table 3. The melting temperature change of HP14 by addition of berberine"

\begin{tabular}{ccccc}
\hline Mole ration & $1: 0$ & $1: 1$ & $1: 3$ & $1: 5$ \\
\hline$T_{n}\left({ }^{\circ} \mathrm{C}\right)$ & 64.0 & 64.1 & 64.7 & 63.2 \\
\hline
\end{tabular}

"Solution conditions were $50 \mathrm{~m} . \mathrm{M}$ sodium phosphate (pH 7.0 ), $100 \mathrm{mM}$ $\mathrm{KCl}$ and $0.1 \mathrm{mM}$ EDTA. "Tw values were derived from UV melling profiles in the absence and presence of berberine at a [HPl4]: [berberine] ratio. [ach $f_{m}$ value is an average derived from at least two independent experiments. 
that shift upon binding correspond to the residues directly involved in recognition. chenical shift changes can provide valuable insights into the structural basis for recognition. and should serve to guide design or screening efforts focused on the discovery of novel ligands. Differences in DNA binding mode of protoberberine analogs, berberine and berberrubine. are clearly manifested through chemical shift deviation of drug resonance after addition of drugs to HPI4 (Table 2). Compared to the berberrubine. the chemical shift change of the berberine shows no specific trend. The shift variation effect must be considered as the sum of specific and nonspecific interactions. The external nonspecific ionic interactions of the positively charged berberine molecule with the negatively charged ionic surface of the oligonucleotide appear inportant.

For berberine. substantially broader lines are evident. reflecting clear differences in the DNA binding interactions. Notably, increased line widths due to internnediate time scale motions also are conmon in biomolecular complexes ${ }^{3(1.33}$ This phenomenon underscores the inportance of mobility. Despite the lower resolution of spectra for berberine. some specific information regarding binding mode and orientations is available. Iniportantly the lack of specificity of upfield changes in chemical shift for the protons of the berberine ligand upon binding the oligonucleotide is indicative of non-specific interaction between the berberine and HPI4.

There is very little preexisting information about the sequence specificity of protoberberine analogs. In contrast to results observed for oligonucleotide interactions with strong intercalator. such as ethidium salt $\hat{t}^{* 4}$ and ellipticine..$^{1 \hat{2}}$ significant internuptions in sequential base-to-sugar NOE connectivities are not evident in duplex DNA bound by the berberine. There are several explanations for this. any of which may be operating in concert: (i) the exchange dynamic, with its inherent line width relationship, simply does not afford sufficient signal to noise ratios, (ii) the berberine simply binds DNA less specifically than berberrubine. The combination of faster exchange kinetics and the lack of specific trend on chemical shift change of the berberine certainly suggests a relatively low level of sequence selectivity

Despite the potential for contact between the HP 14 and the berberine ligand, few internnolecular NOEs were evident. It is interesting that berberrubine with HPI4. a multitude of such contacts are visible, ${ }^{-\delta}$ even under intermediate exchange conditions. To a first approximation. this contrast illustrates quite dramatically the effect of the structural difference of ligand on their DNA binding behavior. The larger methoxy substituent on 19-position of berberine may lead to more canted geometries for intercalation so as to mininize stacking. Such a binding geometry would put the berberine further away from the base stacking of the DNA, where the potential for intercalative DNA contact is reduced. If the berberine ligand spends little time in any one location in space. then there is also little time for NOE buildup. The observation of few specific intermolecular NOEs between the berberine and the oligonucleotide suggests that some binding preferences are expressed for certain base steps of the oligonucleotide under NMR conditions. ${ }^{36}$ The quality of spectra of berberine-HPl 4 however precludes any comments on binding preferences for this protoberberine analog.

Consolidation of UV Results and NMR Data. While Detailed three-dimensional structural model of the berberine bound to HPI4 is, of course, not possible to develop without extensive NOE constraints, we may explore and discriminate among possible DNA biding mode based upon chemical shift deviation and UV data.

UV studies provided the evidence that the berberine binds nonspecifically into DNA. Here we have confinmed this result and we have extended our understanding of the structural details of the drug interactions with the DNA oligonucleotide. Several observations support non-specific binding by the berberine: (i) nonspecific upfield changes in ${ }^{1} \mathrm{H}$ chemical shift for protons of the berberine ligand; (ii) very small increases in duplex melting temperature in the presence of the berberine. The broadening of imino protons upon binding of the berberine is also consistent with non specific binding. The consistency of nonspecific binding developed based upon NMR and UV data is also notewortly given the different time scales for the two experiments. Importantly. these NMR data now provide a structural context for UV results and illustrate again the utility of NMR spectroscopy in describing ligand-DNA interactions.

Correlation between DNA Binding Mode and Topoisomerase II Poisoning Ability. The ability of certain protoberberine alkaloid to act as topoisomerase II poisons was linked to the anti-cancer activity. Minor alterations in structure had a significant effect on the relative activity of protoberberines. Berberine, which has methoxy group at the 19-position. is significantly less potent than berberrubine. ${ }^{16}$ Our results reveal that substitution of a lydrosyl group to a methosy group on the 19-position in a protoberberine analog. thereby converting the berberrubine to the berberine (see Figure 1), is associated with a non-specific DNA binding affinity and a reduced TOPII poisoning. This replacement of a hydrosyl groups in the 19-position by a methosy group could disturb DNA binding by berberine. The presence of a bulky 19-methoxy substituent decreases intercalating properties of berberine and makes it inactive as topoisomerase II poison. These results are well consistent with the previous reports that the "mixed-mode" DNA binding model for protoberberines proposed by Pilch $e t a .^{37}$ both intercalative and minor groove binding. is important for topoisomerase II poisoning activities, which could possibly account for the lack of topoisomerase II poisoning by the berberine.

Acknowledgement. This work was supported by a grant from Korea Basic Science Research Institute program of the Korean Research Foundation (W. Lee. 2001-015-DP0289).

\section{References}

1. Wang. T. C. Anmu. Ren Biochem. 1985. 54. 665. 
2. Osheroti. N. Phamacol. Ther: 1989. 41.223.

3. Champoux. J. J. Mecthanistic Aspect of Type-I Topoisomerases. In DNA Topologt and Its Biological Effects: Cozzarelli, N. R. Wang. I. C., Eds:- Cold Spring Harbor Laboratory Press: Cold Spring Harbor NY. U. S. A.. 1990; p 217.

4. Hsieh. T. Mechamistic Aspect of Type-I Topoisomerases. In DNA Topology amd Its Biological Effects: Cozzarelli. N. R. Wang. J. C.. Eds.: Cold Spring Harbor Laboratory Press: Cold Spring Harbor. NY. U. S. A.. 1990: p 242

5. Liu. L. F. Anmi. Rev Biodhem. 1989. 68. 351.

6. Liu. L. F. Mechanistic Aspect of Tupe-I Topoisonterases. In DNA Topology amd Its Biological Effects: Cozzarelli. N. R. Wang. J. C. Eds.: Cold Spring Harbor Laboratory Press: Cold Spring Harbor. NY.. U. S. A.. 1990: p 371

7. Schneider, E.: Hsiang, Y.-H: Liu, L. F. Adt: Pharmacol 1990. 21. 183

8. Ishida. K: Asso. T. Biochim. Biophns .Acta 2002, $1587,155$.

9. Reece. R. J.: Maxwell. A. Crit. Rev Biochem. Hol. Biol. 1991. 26. 335 .

10. Maxwell. A. J. Antmicrob. Chemother. 1992. 30.409.

11. Corbett. A. H.: Osherott N. Chent. Res. Toxicol. 1993, 6. 585.

12. Monnot, M.: Mauffret. O.: Simon. V; Lescot. E.; Psaume, B.: Saucier I. M.: Charra. M: Belehradek, I.. J.: Fermandjian. S. $J$. Biol. (Chem. 1991. 266.1820.

13. Gatto. B.: Sanders. M. M.: Yu. C.: Wu. H. Y: Makhey. D.: LaVoie. E. J.: Liu. L. F. Gancer Res. 1996. 56. 2795.

14. Makhey. D.; Gatto. B.; Yu, Y. C.: Liu, A.: Liu, L. F; La Voie, E. I. Bioorg lifed Chent 1996,781 .

15. Li, T. K.: Bathor: E; LaVoie, E. J.: Srinivasan. A. R.: Olson, W. K.: Sauers. R. R.: Liu. L. F.: Pilch. D. S. Biochemishy 2000. 39. 7107

16. Kim. S. A:: Kwon. Y: Kim. J. H.: Muller. M. T.: Chung. I. K. Biochentistry 1998. 37. 16316.

17. Ikekawa T: Ikeda. Y. J. Pharmacobiodn 1982, $5,469$.

18. Long. B. H.: Balasubramanian, B. N. Expent Opin. Ther Pat.
2000. 10.635

19. Ogiso. Y: Tomida. A.: Lei. S.: Omura. S.: Isuruo. I. Cancer Res. 2000. 60,2429 .

20. Saran. A.; Srivastava, S.; Coutinho. E; Maiti, M. Indian J. Biochem. Biophws $1995,32,74$.

21. Li. W.-Y.: Lu. H.: Xu. C.-X.: Zhang. T.-B.: Lu. Z.-H. Spectrosc Lett. 1998.31 .1287$.

22. Rer1. J.: Chaires. B. Biochemisty 1999. 38. 16067.

23. Kumar. A.: Wagner. G.; Ernst. R. R.: Wuthrich, K. Biochent Biophus Res. Comm 1980. 95, 1.

24. Bax. A.: Davis, D. G. J. Hagn. Reson, $1985,65,355$.

25. Nagayama. K.: Kumar. A.: Wüthrich. K.: Em1st. R. R. J. Magn. Reson. 1980. 40.321

26. Petersheim. M.: Tumer. D. H. Biochemistry 1983. 22.256

27. Wuthrich. K. MR of Proteins and Nucleic Acids: Wiley: New York. NY. U. S. A.. 1986.

28. Unpublished data.

29. Jeonl. Y. W.: Jung. I. W: Kang. M: Chung. I. K.: Lee. W. Bull. Konam Chem. Soc. 2002. 23.391.

30. Qianl. Y. Q.: Otting. G.: Billeter. M.: Muller. M.: Gehring. W.: Wüthrich. K. J. Mol. Biol. 1993. 234, 1070.

31. Kay, L. E.: Muhandiram, D. R.: Farrow: N. A.; Aubin. Y.: FonmanKay, J. D. Biochemistry 1996, 35. 361

32. Brodshy. A. S.: Williamson. J. R. J. M Hol Biol. 1997. 267.624

33. Foster. M. P.: Wuttke. D. S.: Case. D. A.: Gottesteld. J. M.: Wright. P. E. Kat. Sotuct. Biol. 1997. f. 605.

34. Davies, D. B.: Baranovsky. S. F.: Veselkov, A. N. J. Chem. Soc. EARALAY Trans 1997,93(8). 1559 .

35. Xu. Z.: Pilch, D. S.; Srinivasan, A. R; Olson. W. K; Geacintov. N. E.: Breslauer. K. J. Bioorg. 11ed. Chem 1997. 5. 1137.

36. Mazzini. S.: Bellucei. M. C.: Mondelli. R. Bioorg. Med. Chem. 2003. 11. 505

37. Pilch. D. S.: Yu. C: Makihey. D.; La Voie. E. J.: Srinivasan, A. R.: Olson. W. K.: Sauers. R. R.; Breslauer. K. J:- Geacintov. N. E: Liu. L. F. Biochentistry 1997.36. 12542. 